\title{
Mechanical and Thermal Properties Analysis of Polypropylene Reinforced With Polyamide Microfibre Obtained From Shredded Tyres
}

\author{
Parres F.*, Crespo-Amorós J.E., Nadal-Gisbert A., and Navarro R. \\ Department of Mechanical and Materials Engineering, Universitat Politècnica de València, Plaza Ferrandiz y Carbonell, \\ 2; 03801; Alcoy - Alicante, Spain
}

Received: 18 July 2011, Accepted: 24 July 2012

\begin{abstract}
SUMMARY
The importance of recovering waste materials generated by industrialised societies is mainly due to the environmental impact that they have, and one of the principal problems is the presence of end of life tyres. The use of waste microfibre obtained from shredded tyres as reinforcement in polypropylene matrices offers an interesting opportunity for recycling of the waste microfibre, in order to obtain 'value added products' from polypropylene (PP)/waste microfibre tyre composites. The microfibres obtained from shredded tyres were used as a reinforcing material in compositions with polypropylene (PP). The blending proportions were: (1) $10 \%$ microfibre $90 \% \mathrm{PP}$; (2) $20 \%$ microfibre, $80 \% \mathrm{PP}$; (3) $30 \%$ microfibre, $70 \% \mathrm{PP}$; (4) $40 \%$ microfibre, $60 \% \mathrm{PP}$, (5) $50 \%$ microfibre, $50 \% \mathrm{PP}$ and (6) $80 \%$ microfibre, $20 \% \mathrm{PP}$. The mechanical and thermal properties were analyzed. In this case polypropylene mixed with polyamide (PA) microfibres show a decrease in tensile strength and elongation at break, however, impact strength and Vicat Softening temperature values increase with polyamide microfibre content. Continuity in the matrix phase was observed by scanning electron microscopy up to loadings of $40 \%$ microfibre.
\end{abstract}

Keywords: Microfibres, Recycled, Tyre, Polypropylene

\section{INTRODUCTION}

In recent years, the re-use of waste materials has become extremely important for two main reasons: economic and environmental. With the first of these, the recovery of material often means a reduction in manufacturing costs of certain products which enables them to compete with virgin products. However, it is the second reason, the environmental impact factor, which is assuming greater importance nowadays. Over the last decade many governments have imposed legislation to deal with this problem. In the case of thermoplastics, recovery processes are generally easy and the simple use of heating allows us to get new products with similar characteristics to the original ones. On the other hand the recovery of other materials such as tyres is more

*Corresponding author: fraparga@dimm.upv.es - Tlf: +034 966528570

${ }^{\circledR}$ Smithers Rapra Technology, 2012 complicated as new tyres can not be manufactured by recycling old ones. One of the solutions adopted has been the use of recycled tyres in other applications such as acoustic insulation, flooring for children's parks and other products obtained from shredded tyres ${ }^{1,2}$. In the tyre recovery process several types of fibres are also obtained, including fibres incorporated in the tyres for reinforcement.

The identification and characterization of fibres from shredded tyres was made using various techniques such as differential scanning calorimetry, thermogravimetry and pyrolysis-gas chromatography/mass spectrometry, where the existence of two different morphologies of fibre, cord and microfibre $^{3}$ was observed. These fibres were used as reinforcement in plaster, achieving good results for concentrations of two fibre and microfibre weight percentage ${ }^{4}$.

Fibres in general, have been used by several authors in order to improve the mechanical properties of fragile materials ${ }^{5,6}$. In ceramic materials, fibre helps prevent the progression of cracks from their origin and also avoids the piece breaking completely in two $0^{7,8}$. Polypropylene has been used by many authors as a matrix phase in the study of composite materials, the fibres used in these studies were of different origin, natural and synthetic ${ }^{9-14}$.

Currently, microfibres obtained from shredded tyres are burned to obtain energy, as they have a high calorific value, although this process has the disadvantage that it produces large quantities of $\mathrm{CO}_{2}$. As an alternative to this, the aim of this research has been the use of microfibres from shredded tyres as polypropylene reinforcement. 


\section{EXPERIMENTAL}

\subsection{Materials}

The materials used in this work are virgin Polypropylene (PP) and polyamide microfibre obtained from shredded tyres. Virgin PP Isplen ${ }^{\circledR}$ PR 290 P1M in pellet form supplied by REPSOL YPF, Madrid - Spain. The microfibres derived from the tyre shredding process were supplied by RMD S.A., Ardoncino, León - Spain.

Table 1 shows some characteristics of the materials used in this work.

\subsection{Sample Preparation}

The blends were prepared using a tworoll mill (front roll $160-170{ }^{\circ} \mathrm{C}$; rear roll $\left.170-180^{\circ} \mathrm{C}\right)$. The blending process was conducted with different amounts of PP and PA microfibre. Before mixing, the microfibres were dried at $80^{\circ} \mathrm{C}$ for 4 hours. The mixing process was performed with the addition of small amounts of polypropylene and microfibre alternately. Once the blend was obtained, sheets with a thickness of around $4-10^{-3} \mathrm{~m}$ were prepared on a hot plate press, with a pressure of $5 \mathrm{MPa}$, applying a temperature of $180^{\circ} \mathrm{C}$ over $5 \mathrm{~min}$, followed by a cooling period of 10 min until the temperature dropped to $40{ }^{\circ} \mathrm{C}$.

\subsection{Characterization}

The mechanical properties of the samples were evaluated using an ELIB 30 electromechanical universal testing machine from Ibertest (S.A.E. Ibertest, Madrid, Spain). A $10 \mathrm{~mm} \mathrm{~min}^{-1}$ crosshead speed was used to determine the elongation at break and tensile strength, with a load cell of $5 \mathrm{kN}$. All tests were carried out following UNEEN ISO 527 standard. All specimens were tested at room temperature. Impact energy was determined by using a Charpy impact machine (S.A.E. Ibertest, Madrid, Spain) according to ISO 179. A minimum of five samples was analysed in order to obtain every result.

To determine the Vicat softening temperature, a Vicat/HDT model Deflex 687-A2 (Metrotec, S.A, San Sebastian, Spain) was used. The oil used for the softening was silicon DOW Corning 200 Fluid 100 CS. The development of the test was carried out according to ISO 306.

The fracture surfaces appearing in the material after the tensile strength tests were analysed by scanning electron microscopy with a HITACHI S-3000N Scanning Electron Microscope(Hitachi Ltd. Japan). Image acquisition was taken after gold sputter coating under vacuum conditions on the surface of the samples.

\section{RESULTS AND DISCUSSION}

\subsection{Mechanical Properties}

The addition of fibre to any matrix, either ceramic or polymer is intended to hinder the fracturing of the material. To act as the reinforcing material, fibre should exhibit a good adhesion capacity in the matrix phase, otherwise the mechanical properties would decrease with increasing fibre percentage.

Table 1. Characteristics of PP and microfibre derived from the tyre shredding process

\begin{tabular}{|l|c|c|}
\hline Material & PP & PA microfibre $^{\mathbf{3 , 4}}$ \\
\hline Melt point, ${ }^{\circ} \mathrm{C}$ & 170 & 260 \\
\hline${\text { Izod Impact Strength, } \mathrm{kJ} \mathrm{m}^{-2}}{ }^{-2}$ & 7 & --- \\
\hline Vicat Softening Temperature, ${ }^{\circ} \mathrm{C}$ & 76 & --- \\
\hline Microfibre length, $\mathrm{mm}$ & & $5 \pm 3$ \\
\hline Microfibre diameter, $\mathrm{mm}$ & & $29.7 \pm 2.3$ \\
\hline
\end{tabular}

In the present study carried out on PP and PA microfibre composites, a graphical representation of the values of tensile strength with PA microfibre revealed a decreasing evolution in the values, and the values showed a very significant decrease when microfibres were added to a polypropylene matrix, in comparison to polypropylene without microfibre. The elongation at break for the system with microfibre (PPmicrofibre PA) also declined rapidly with fibre loading in all microfibre concentrations.

Initially, the microfibre provided by RMD, SA was characterized as containing a certain amount of tyre particles. The incorporation of the PA microfibre in matrix PP phase involved adding a certain quantity of such particles, which act as stress concentrators and it caused a general decline of the mechanical properties (tensile strength and elongation at break) (Figure 1). This could be due to poor adhesion between PP matrix and PA microfibres. These results were analyzed in the morphology study by SEM. In contrast, other authors studied properties of nylon-6 fibre reinforced high density polyethylene (HDPE) and found that the mechanical properties increased with fibre content ${ }^{15}$, but Bipinbal and Sunil found the tensile strength and elongation at break decrease with fibre content for short fibre-natural rubber composites when they used untreated fibres ${ }^{16}$.

In contrast, the application of loads at high speed through the impact test resulted in a positive correlation for all the compositions (Figure 2).

In this case, the presence of rubber particlesimproved theimpactbehaviour of PP composites reinforced with PA microfibre. According to Ahmad et $a l .{ }^{17}$, the presence of elastic particles acts as a good impact modifier and increases the impact strength of the composites. 
Figure 1. Variation of tensile strength and elongation at break of PP reinforced with polyamide microfibre as a function of microfibre content
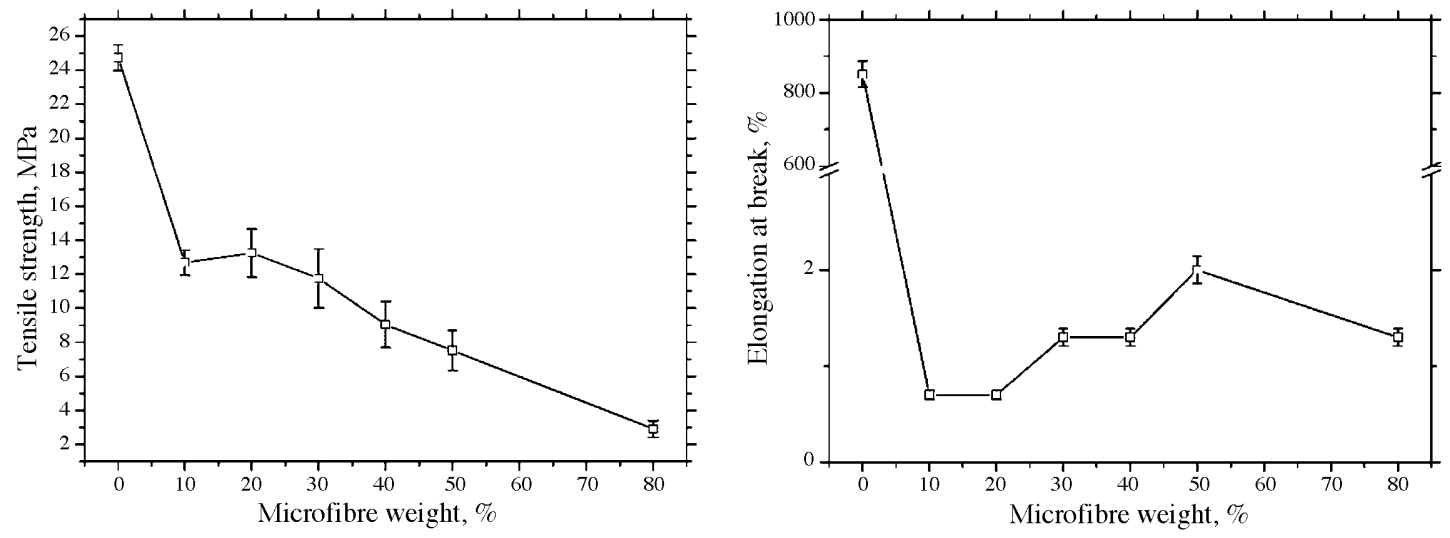

Finally, in the complete mechanical hardness characterization of the materials, the hardness values remained almost constant except for the sample of $80 \%$ microfibre, which presented a decrease of approximately $20 \%$ (Figure 3). This is probably due to low polypropylene content that had bad wettability for the microfibre.

\subsection{Thermal Properties}

Another of the properties that characterize a polymer is the Vicat Softening Temperature (VST), which combines the action of temperature $\left({ }^{\circ} \mathrm{C}\right)$ and $\operatorname{load}(\mathrm{N})$. The results obtained for Vicat softening temperature (VST) of the composite show that the VST values increased with microfibre content (10,20 and 30wt.\%). But, upon using higher percentages of microfibre, a linear decrease of the values was observed (Figure 4). This situation can be explained if we take into account that there is certain microfibre content (higher $30 \mathrm{wt} . \%$ ) that restricts the polypropylene capacity to wet microfibre.

\subsection{Morphological Study}

Surface fracture analysis complemented the results obtained through various tests in the previous section. Figure 5 shows the high elongation at break of virgin PP after tensile test.

Figure 6 shows the SEM micrographs (at 500x magnification) of fractured
Figure 2. Variation of Charpy impact strength of PP reinforced with polyamide microfibre as a function of microfibre content

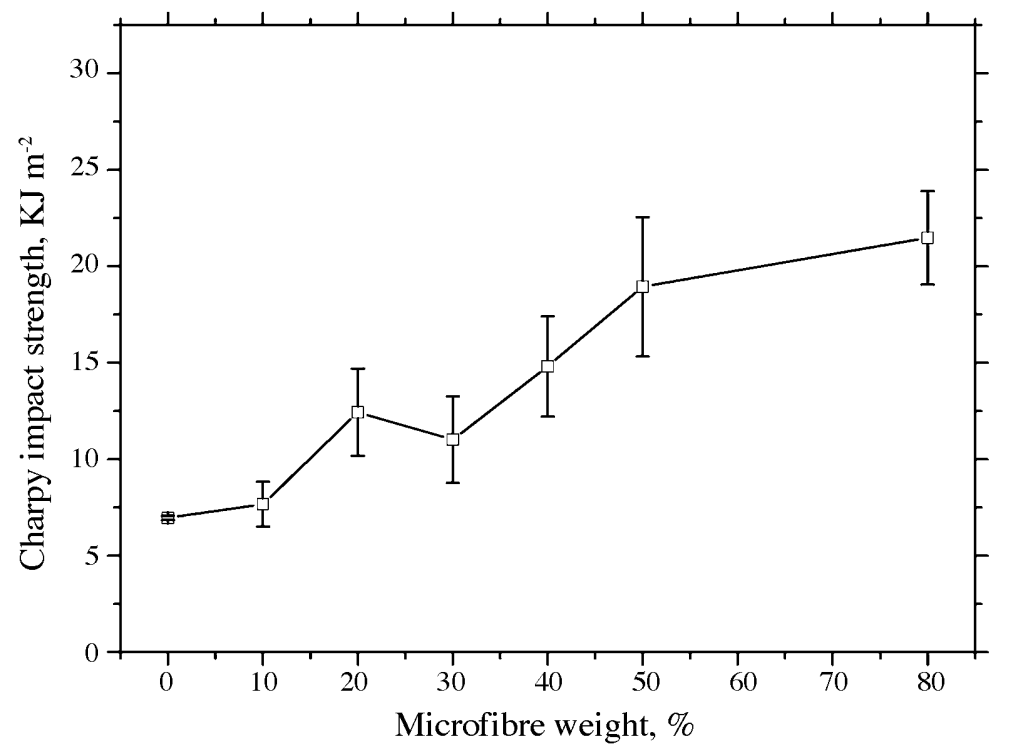

Figure 3. Variation of Shore D hardness of PP reinforced with polyamide microfibre as a function of microfibre content

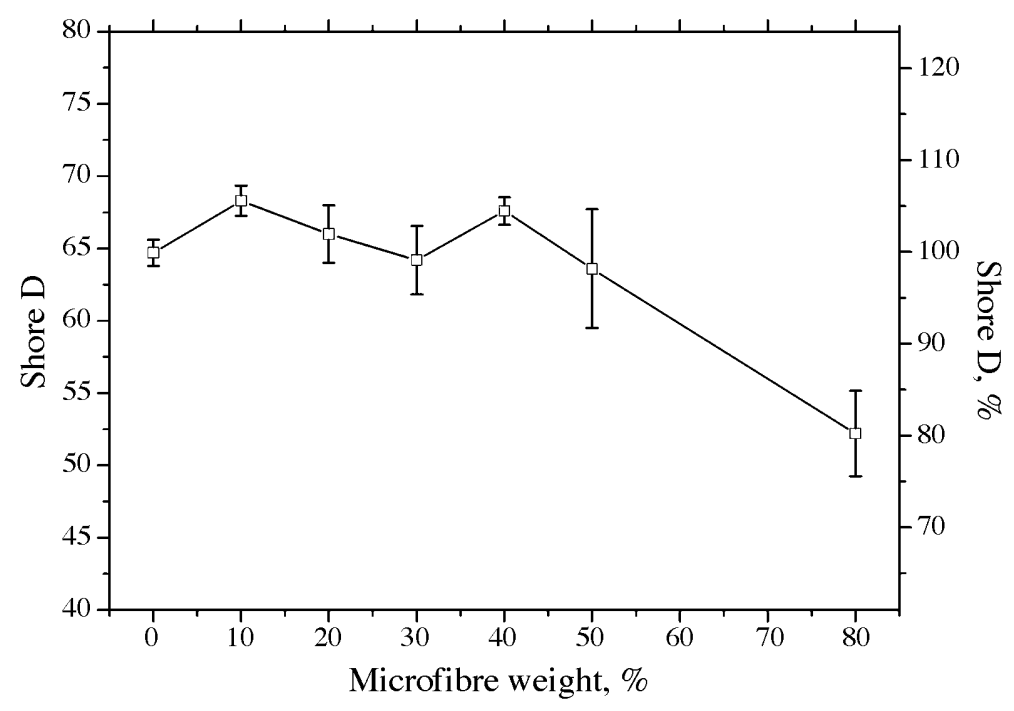


Figure 4. Evolution of the Vicat softening temperature of PP reinforced with polyamide microfibre as a function of the microfibre content

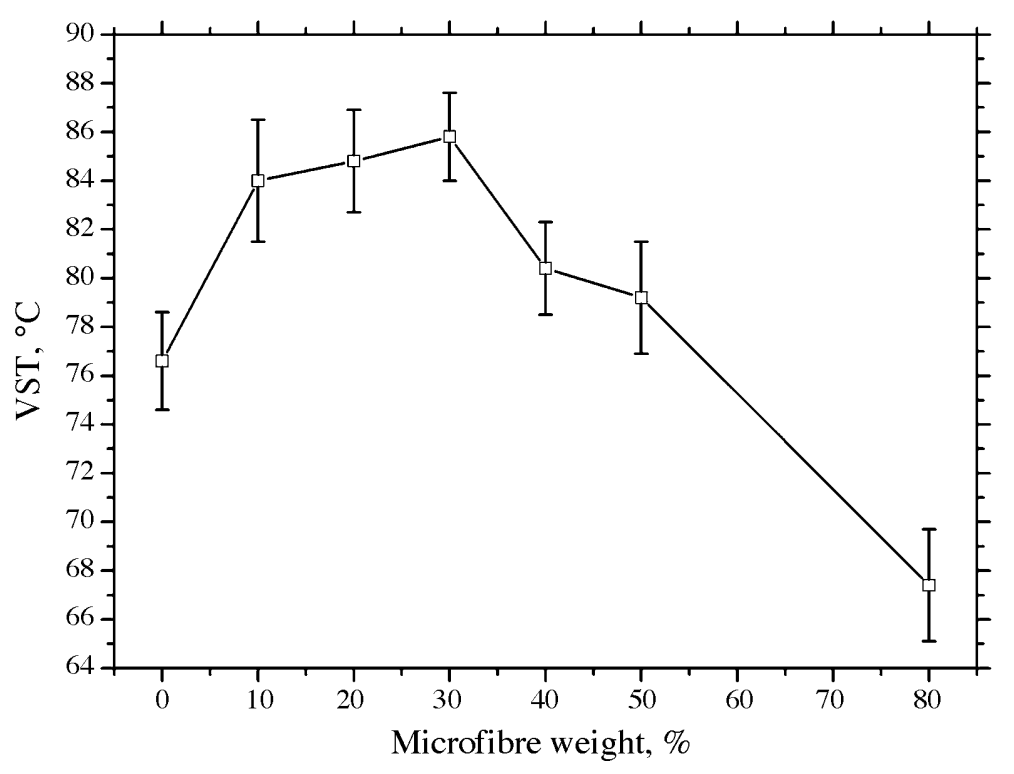

surfaces of the samples with PP at 10 , $20,30 \%$ fibre concentration. In all three cases the set of PA microfibres embedded in the PP matrix phase can be seen. In addition, there are some holes for the start of the microfibre of the PP phase, and this fact demonstrates the lack of adherence between the microfibre and the PP matrix and justifies the drop in the tensile strength and elongation at break.

Furthermore, the addition of higher percentages of $30 \%$ microfibre creates a discontinuity in the total phase matrix of PP, which is difficult to observe at a loading of $80 \%$ microfibre (Figure 7).

\section{CONCLUSIONS}

The properties of binary composites based on PP reinforced with PA

Figure 5. Image of PP virgin after tensile test (a) and detail image of the rupture zone (b)
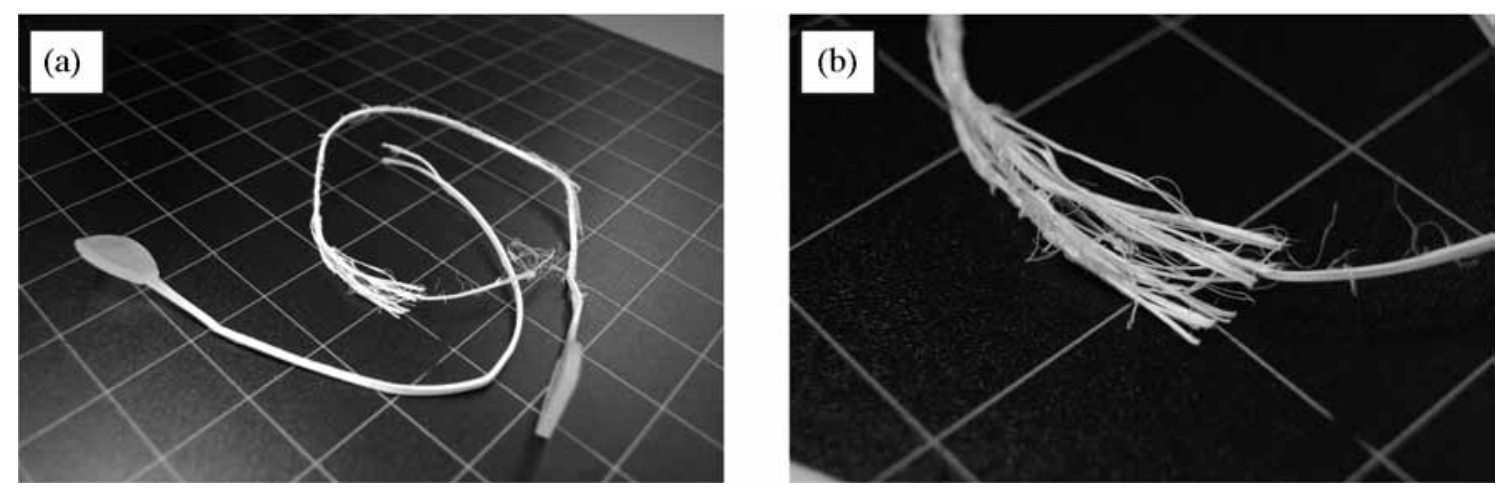

Figure 6. SEM micrograph of fracture surfaces of PP microfibre PA composites, (a) 10 wt. \%, (b) 20 wt.\% and (c) 30 wt.\% (500x)
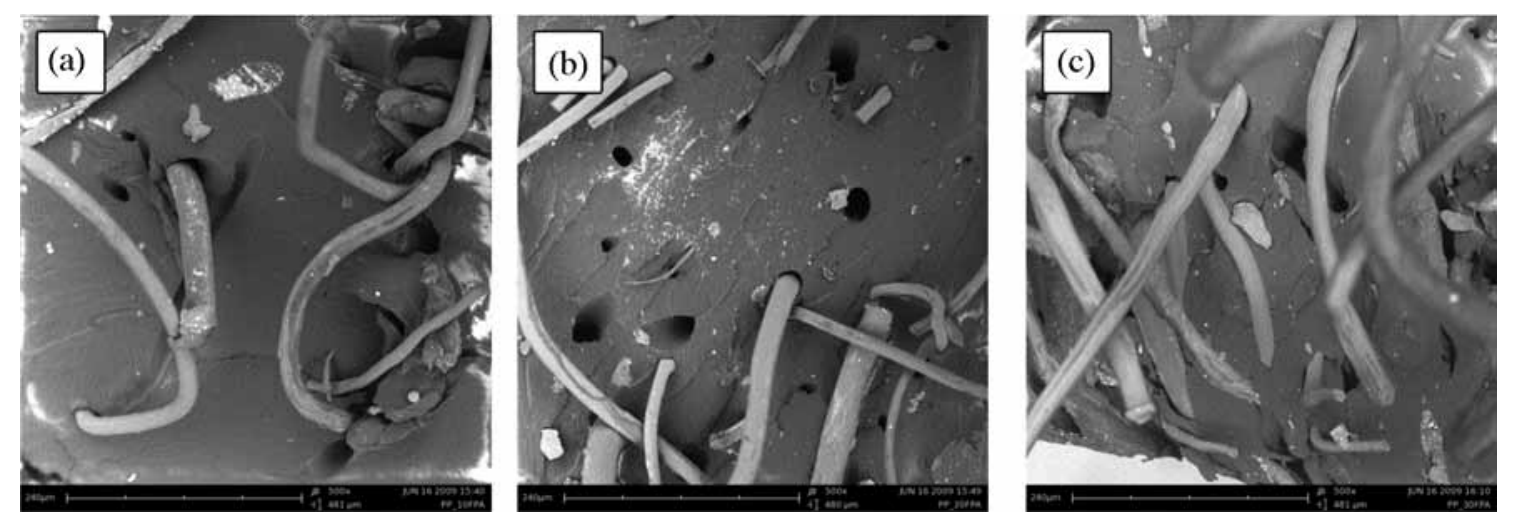
Figure 7. SEM micrograph of fracture surfaces of PP microfibre PA composites, (a) 40 wt.\%, (b) 50 wt.\% and (c) 80 wt.\% (500x)
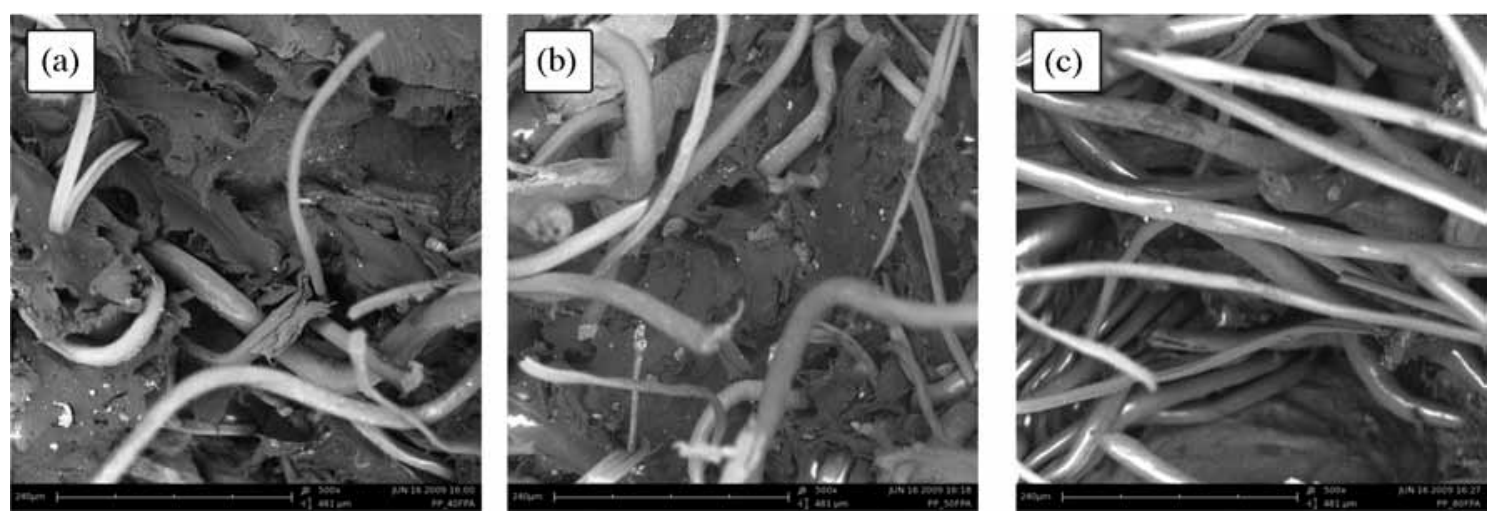

microfibres have been studied in this work.

Firstly, the study revealed that the incorporation of PA microfibre did not improve the tensile strength and elongation at break, due to the low adhesion between matrix and microfibre. However, the values of impact strength increased with microfibre percentage; this was due to the presence of rubber particles in the composite, which produced a decrease of elastic modulus in bending behaviour.

Secondly, the presence of tyre particles in the microfibre was a factor to consider in the case of tensile tests, as tyre particles reduced tensile stress area and consequently the properties declined with increased microfibre content. In contrast, the tyre particles acted as impact modifiers to improve the outcomes for the virgin polypropylene, due to the effect of the rubber particles' presence on the cracks' advance.

Thirdly, the Vicat softening temperature varied with the PA microfibre. We can see two zones: the first zone included 10,20 and $30 \%$ of PAmicrofibre, where the values are similar, and the second zone includes 40,50 and $80 \%$ of PA microfibre where the values decrease linearly as a function of the microfibre concentration.
Finally, the microscopy study confirmed the results of the composite behaviour, where bad adhesion at the microfibre - matrix interface was observed, moreover, a discontinuous matrix could be seen when 40,50 and 80 weight percentages of PAmicrofibre were used. This effect produced a linear decrease of Vicat softening temperature for high microfibre content.

\section{ACKNOWLEDGEMENTS}

The authors would like to thank Carmen Martínez Torres (RMD, S.A.) for the kind donation of the microfibre used in this study.

\section{REFERENCES}

1. Yilmaz A. and Degirmenci N., Waste Management, 29 (2009) 1541-1546.

2. Ayrilmis N., Buyuksari U. and Avci E., Materials and Manufacturing Processes, 24 (2009) 688-692.

3. Parres F., Crespo-Amoros J. E. and Nadal-Gisbert A., Journal of Applied Polymer Science, 113 (2009) 21362142.

4. Parres F., Crespo J. E. and Nadal A., Construction and Building Materials, 23 (2009) 3182-3188.

5. Sezgin E., Ali B. and Erhan S., Journal of Vibroengineering, 11 (2009) 305-315.

6. Ogasawara T., Ishida Y. and Kasai T., Composites Science and Technology, 69 (2009) 2002-2007.
7. del Rio Merino M. and Comino P., Materiales de Construcción, $\mathbf{5 1}$ (2001) 261.

8. Eve S., Gomina M., Gmouh A., Samdi A., Moussa R. and Orange G., Journal of the European Ceramic Society, 22 (2002) 22692275.

9. Ashori A. and Nourbakhsh A., Journal of Applied Polymer Science, 111 (2009) 2616-2620.

10. Cabral H., Cisneros M., Kenny J.M., Vazquez A. and Bernal C.R., Journal of Composite Materials, 39 (2005) 51-65.

11. Gonzalez-Chi P.I., May-Hernandez L.H. and Carrillo-Baeza J.G., Journal of Composite Materials, 38 (2004) 1521-1532.

12. Lee S.Y., Chun S.J., Doh G.H., Kang I.A., Lee S. and Paik K.H., Journal of Composite Materials, 43 (2009) 1639-1657.

13. Rezaei F., Yunus R. and Ibrahim N.A., Materials \& Design, 30 (2009) 260-263.

14. Paul S.A., Joseph K., Mathew G., Pothen L.A. and Thomas S., Polymer Composites, 31 (2010) 816-824.

15. Soundararajan S., Palanivelu K. and Sharma S.K., Journal of Polymer Materials, 24 (2007) 321324.

16. Bipinbal P.K. and Kutty S.K.N., Journal of Applied Polymer Science, 109 (2008) 1484-1491.

17. Ahmad I., Wong P.Y. and Abdullah I., Polymer Composites, 27 (2006) 395-401. 
Reproduced with permission of the copyright owner. Further reproduction prohibited without permission. 